\title{
Influence of fin arrangement on fluid flow and heat transfer in the inlet of a plate-fin heat exchanger*
}

\author{
Jing-cheng LIU $^{\dagger 1}$, Shu-you ZHANG ${ }^{\dagger 1}$, Xin-yue ZHAO ${ }^{1}$, Guo-dong YI ${ }^{1}$, Zhi-yong ZHOU ${ }^{2}$ \\ ( ${ }^{I}$ State Key Laboratory of Fluid Power Transmission and Control, Zhejiang University, Hangzhou 310027, China) \\ ( ${ }^{2}$ Design Institute of National Technology Research Center, Hangzhou Hangyang Co., Ltd., Hangzhou 310004, China) \\ †E-mail: liujc@zju.edu.cn; zsy@zju.edu.cn
}

Received Sept. 4, 2014; Revision accepted Jan. 31, 2015; Crosschecked Mar. 23, 2015

\begin{abstract}
Fin arrangement, which can cause temperature to be distributed non-uniformly and decrease heat exchange efficiency, can also affect fluid flow and distribution in different channels of a plate-fin heat exchanger. To reduce fluid maldistribution, the fluid flow and distribution should be investigated systematically. However, there is as yet no research reported on the fin arrangement effect. We investigated fluid flow and heat transfer at the inlet of a plate-fin heat exchanger by numerical calculation combined with simulation analysis. We simulated the fluid flow under seven kinds of fin arrangement, and analyzed the effects. The distribution of fluid parameters in four monitor positions among three sections was examined when the inlet flow velocity was $1 \mathrm{~m} / \mathrm{s}$ with an inlet structure arranged with different numbers of fins. Denser fin arrangements among inlet, diversion, and heat exchange sections all intensify the turbulence at the outlet. With increase of arrangement density, the fluid flow direction will be changed and the fluid distribution inside the exchanger will be intensified to equalize the fluid temperature in different channels of the same layer. Furthermore, the effects of 18 combinations of fins in different sections on fluid flow were studied. Fin arrangements in different sections have more significant effect on turbulence than flow velocity and pressure; in comparison with the inlet and heat exchange sections, the diversion section has a significant effect on turbulence at the outlet of the heat exchanger.
\end{abstract}

Key words: Fin arrangement, Plate-fin heat exchanger, Heat transfer, Turbulence, Temperature equalization doi: 10.1631 jzus.A1400270

Document code: A

CLC number: TB657

\section{Introduction}

As key components of large-size air separation equipment, plate-fin heat exchangers have direct effects on energy consumption and efficiency of the units. As is known fins are important in the heat exchanging structure because their arrangements will not only affect fluid flow and distribution in channels, but also heat exchange efficiency of the whole. There has been some studies on fin structure, fluid turbu-

\footnotetext{
ॠ Corresponding author

*Project supported by the National Basic Research Program (973) of China (No. 2011CB706506), the National Natural Science Foundation of China (No. 51375438), and the Zhejiang Provincial Natural Science Foundation of China (No. LQ13F030003)

(10) ORCID: Jing-cheng LIU, http://orcid.org/0000-0002-5603-2146; Shu-you ZHANG, http://orcid.org/0000-0001-9023-5361

(C) Zhejiang University and Springer-Verlag Berlin Heidelberg 2015
}

lence, and the enhancement of heat transfer in heat exchangers. Some significant conclusions have been drawn.

Previous studies used Bayesian statistics (Gnanasekaran and Balaji, 2011), regularized iteration (Yang and Chen, 2009), Adomian decomposition (Kundu et al., 2012), and other methods (Lozza and Merlo, 2001; Yang et al., 2007) to analyze fluid flow and heat transfer in heat exchangers with pin fins (Sahiti et al., 2005) and corrugated fins. Wongwises and Chokeman (2005) studied the spatial effects of fins and columns of tubes on the performance of a herringbone corrugated tube-fin heat exchanger, and revealed the relationship between fin space and heat transfer performance. Liu et al. (2012) focused on fluid flow and heat transfer in a micro-channel of different geometries, and constructed the rules of 
fluid flow in micro-channels. Ma et al. (2011) studied the enhancement of heat transfer in a serrated spiral finned tube, and concluded the effects of longitudinal pitch of a finned tube on heat exchange and flow resistance characteristics in tube bundles.

In an analysis of fluid turbulence and heat transfer, Hu and Zhang (2007) proposed an improved $k-\varepsilon$ analysis model for gas and liquid-phase flow and heat transfer. Li et al. (2011) studied the enhanced heat transfer mechanism of roughness in the process of turbulent and convective heat transfer, and found that there always exists a maximum Nusselt number in the process of convective heat transfer associated with increase of Reynolds number. Yang and Hwang (2009), Gao et al. (2012), and Wu et al. (2012) adopted the method of numerical simulation and analyzed fluid flow and heat transfer in heat exchangers, and then found the change rules of Nusselt number and friction factor.

For heat transfer enhancement, Lin et al. (2004) and Zhang et al. (2007) focused on the problems of low efficiency and fouling deposit in heat exchangers, and developed rotating twisted tape technology for enhancement of heat transfer and on-line cleaning. Wang et al. (2007) conducted a large eddy simulation according to fluid flow and heat transfer characteristics in the rectangular channel of an inclined-cut ellipsoidal vortex generator and discovered the structure of fluid flow and the mechanism of heat transfer enhancement in the vortex generator. $\mathrm{He}$ and Tao (2009) studied the mechanism of heat convection enhancement, pointed to a direction of research on the theory of field synergy, and developed two types of finned tube with an enhanced heat-transfer surface based on this theory. Zhang et al. (2014) summarized the development of large-scale air separation and compared the main technical parameters of the domestic and international high-pressure plate-fin heat exchangers.

It can be concluded from the above that the effects of fin arrangement on fluid flow and heat transfer in heat exchangers are rarely analyzed or reported. However, with the development of air separation equipment to larger sizes and lower energy consumption, plate-fin heat exchangers need to meet high requirements for fluid flow and heat transfer internally. Generally, fin arrangements at the inlet have the following effects on fluid flow and heat transfer:

First, fin arrangements affect the pattern of fluid flow. As the contact position and number of fins vary in different sections, there may be turbulence in some positions changing the flow type and affecting the fluid turbulence in channels.

Second, fin arrangements affect the temperature distribution. The fin has a certain thickness, and, under the same inlet conditions, channels will be narrower if fins are arranged more densely, which will increase the flow rate, and finally, a large amount of fluid can flow out of channels without fully transferring heat, thus decreasing heat transfer efficiency in the exchanger.

With a trend of air separation equipment becoming larger and of lower consumption, heat transfer enhancement of the heat exchanger has become key issue. Therefore, it is important that we can select a proper fin arrangement at the inlet to ensure even temperature distribution of fluid and improve heat transfer efficiency. We focus on the effects of seven types of fin arrangement in different sections at the inlet of a plate-fin heat exchanger on fluid flow and heat transfer.

\section{Plate-fin heat exchanger model and mathematical formulation}

\subsection{Physical model}

The 3D channel structure of a plate-fin heat exchanger is shown in Fig. 1. The plate-fin heat exchanger is a multi-layer composite structure overlaid with separating plates and fins of similar geometry. The cross section of single-layer fins is usually rectangular, and generally, fins are evenly distributed in the exchanger. Since the number of fins varies in different sections, fluid may be mixed in the positions where sections are contacted. For a better analysis of the effects of fin number in different sections on fluid flow, the inlet part of the plate-fin heat exchanger is preliminarily divided into three sections: the inlet section, the diversion section, and the heat exchange section.

Among the three sections, the diversion section is mainly used for fluid reallocation, and the heat 
exchange section, as the main part for heat transfer, completes the heat exchange between cold and hot fluids by heat transfer through fins and separating plates.

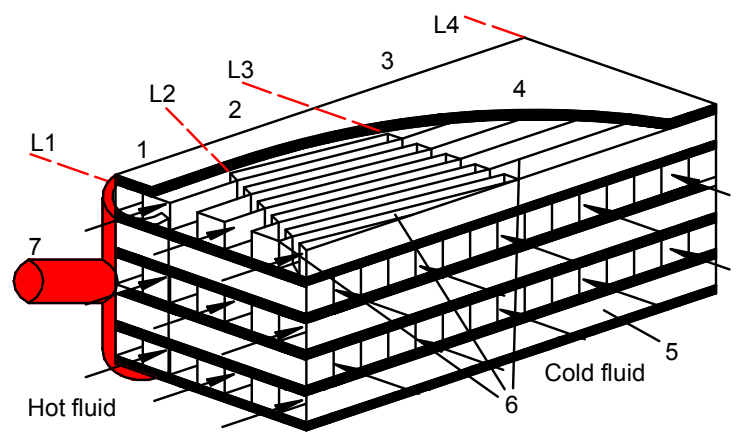

Fig. 1 Inlet structure of plate-fin heat exchanger 1: inlet section; 2 : diversion section; 3 : heat exchange section; 4: separate plate; 5: seal; 6: fin; 7: head; L1, L2, L3, and L4 are four monitoring positions

The cross section of channels in various sections is rectangular, and commonly used fins are of the straight type. Generally, the number of fins varies in different sections and affects the temperature distribution of fluid in the exchanger. Therefore, computational fluid dynamics (CFD) software, Fluent, was used to simulate fluid flow in the inlet structure.

\subsection{Mathematical formulation}

Fluid flow in channels is simulated based on the assumptions of having a continuous medium with the equations of continuity, momentum conservation, and energy conservation. For better analysis of heat exchange inside the plate-fin exchanger, the following assumptions are proposed:

(a) The fluid is incompressible; (b) fluid at the inlet is under turbulent flow; (c) physical properties of the fluid do not change with temperature; (d) viscous dissipation of fluid is ignored; (e) fluid flows evenly in channels at the inlet; (f) channels formed by fins are evenly spaced; (g) heat exchange between the internal fluid and external air is ignored; (h) frictional resistance and loss of fluid caused by fin structure is ignored; (i) differences in fluid temperature distribution between channels in the same cross section of fin structure on the same layer are ignored.

According to the heat exchanger model created in Fig. 1 and the above assumptions, the model treats fluid and thermo exchange as a closed system. This system consists of the inlet section, the diversion section, and the heat exchange section. The number of fins varies in the three sections resulting in fluid maldistribution and temperature non-uniformity in different channels of the same cross section. The equations of continuity, momentum equation (Qiu et al., 2010), and energy equations (Qiu et al., 2010) for fluid flow are listed below:

Continuity equation:

$$
\frac{\partial \rho}{\partial t}+\frac{\partial\left(\rho U_{i}\right)}{\partial t}+\frac{\partial\left(\rho U_{j}\right)}{\partial t}=0
$$

Momentum equation:

$$
\rho U_{i} \frac{\partial U_{j}}{\partial x_{i}}=-\frac{\partial P}{\partial x_{j}}+\frac{\partial}{\partial x_{j}}\left(\left(\mu+\mu_{\mathrm{t}}\right) \frac{\partial U_{j}}{\partial x_{i}}+\frac{\partial U_{i}}{\partial x_{j}}\right)+S_{\mathrm{p}},
$$

where $U$ is the fluid flow rate; $x$ and $y$ are coordinate axes corresponding to the flow rate; $\mu$ is the frictional resistance loss coefficient; $\mu_{\mathrm{t}}$ is the turbulent viscosity; $\rho$ is the fluid density; $P$ is the flow pressure; $S_{\mathrm{P}}$ is the generalized source item of momentum equation; subscripts $i$ and $j$ are flow directions. In the exchanger, the turbulent flow (Liu et al., 2014) can be calculated as

$$
\begin{aligned}
\rho k \frac{\partial U_{i}}{\partial x_{i}}= & \frac{\partial}{\partial x_{i}}\left(\left(\mu+\frac{\mu_{\mathrm{t}}}{\sigma_{k}}\right) \frac{\partial k}{\partial x_{i}}\right) \\
& +\mu_{\mathrm{t}}\left(\frac{\partial U_{j}}{\partial x_{i}}+\frac{\partial U_{i}}{\partial x_{j}}\right) \frac{\partial U_{i}}{\partial x_{j}}-\Gamma, \\
\Gamma \frac{\partial U_{i}}{\partial x_{i}}= & \frac{\partial}{\partial x_{i}}\left(\left(\mu+\frac{\mu_{\mathrm{t}}}{\sigma_{\varepsilon}}\right) \frac{\partial \varepsilon}{\partial x_{i}}\right) \\
& +C_{1} \rho \mu_{\mathrm{t}} \frac{\varepsilon}{k}\left(\frac{\partial U_{j}}{\partial x_{i}}+\frac{\partial U_{i}}{\partial x_{j}}\right) \frac{\partial U_{i}}{\partial x_{j}}-\rho C_{2} \frac{\varepsilon^{2}}{k},
\end{aligned}
$$

in Eqs. (3) and (4),

$$
\mu_{\mathrm{t}}=\rho C_{\mu} k^{2} / \varepsilon
$$

where $k$ is the fluid turbulence energy $\left(\mathrm{m}^{2} / \mathrm{s}^{2}\right) ; \Gamma=\rho \varepsilon$ is the turbulence dissipation rate of turbulent kinetic energy; $\varepsilon$ is the turbulence dissipation rate $\left(\mathrm{m}^{2} / \mathrm{s}^{3}\right)$; 
and $C_{1}, C_{2}, C_{\mu}, \sigma_{k}$, and $\sigma_{\varepsilon}$ are constants:

$$
C_{1}=1.44, C_{2}=1.92, C_{\mu}=0.09, \sigma_{k}=1.0, \sigma_{\varepsilon}=1.0 .
$$

Energy equation (Liu et al., 2014):

$$
\begin{aligned}
\frac{\partial(\rho T)}{\partial t} & +\frac{\partial\left(\rho U_{x} T\right)}{\partial x}+\frac{\partial\left(\rho U_{y} T\right)}{\partial y} \\
& =\frac{\partial}{\partial x}\left(\frac{K}{C} \frac{\partial T}{\partial x}\right)+\frac{\partial}{\partial y}\left(\frac{K}{C_{\mathrm{p}}} \frac{\partial T}{\partial y}\right)+S_{\mathrm{E}}
\end{aligned}
$$

where $T$ is the fluid temperature; $K$ denotes the overall heat transfer coefficient; $C$ is the constant; $S_{\mathrm{E}}$ is the part of kinetic energy converted into heat during fluid motion; and $C_{\mathrm{p}}$ is the specific heat capacity of the fluid under constant pressure.

To simplify the analysis, it is assumed that the outside wall of the exchanger is insulated; there is no sliding mesh on the fin structure and wall, and the wall temperature is constant.

Channels in the exchanger are divided into different sections. The flow equation of fluid in these sections is

$$
\sum_{i_{0}=1}^{l_{\max }} l_{i_{0}} q_{i_{0}}=\sum_{i_{0}=1}^{m_{\max }} m_{i_{0}} q_{i_{0}}=\sum_{i_{0}=1}^{n_{\max }} n_{i_{0}} q_{i_{0}},
$$

where $l, m$, and $n$ represent the number of channels in the inlet, diversion, and heat exchange section, respectively; $q$ is the flux in each channel $\left(\mathrm{m}^{3} / \mathrm{s}\right)$; and the subscripts $i_{0}$ and max represent the number and the maximum of the number of channels in the three sections.

The heat transfer $Q$ can be expressed in Eq. (7). Newton's equation of heat convection of fluid in the sections is shown in Eq. (5).

$$
\Delta Q=Q_{\text {in }}-Q_{\text {out }}=h A \Delta T_{\text {avg }}
$$

where $h$ is the specific enthalpy of the fluid; $A$ is the heat exchange area; and $\Delta T_{\mathrm{avg}}$ is the logarithmic mean temperature difference of fluid in the exchanger. It can be calculated as

$$
\Delta T_{\mathrm{avg}}=\frac{\Delta T_{\max }-\Delta T_{\min }}{\ln \left(\Delta T_{\max } / \Delta T_{\min }\right)}
$$

$$
\begin{aligned}
\Delta T_{\text {max }} & =\max \left(T_{\mathrm{hi}}-T_{\mathrm{co}}\right), \\
\Delta T_{\text {min }} & =\min \left(T_{\mathrm{ho}}-T_{\mathrm{ci}}\right),
\end{aligned}
$$

where $T_{\mathrm{hi}}$ and $T_{\mathrm{ci}}$ is the inlet temperature of hot channel and cold channel; $T_{\text {ho }}$ and $T_{\text {co }}$ is the outlet temperature of hot channel and cold channel, and $\Delta T_{\max }$ and $\Delta T_{\min }$ is the maximum and minimum of the mass-averaged temperature at the outlet of the exchanger, respectively.

Pressure loss may occur in various sections and during flow inside the exchanger.

Pressure variation (Gullapalli and Sundén, 2014) in the channel can be expressed as

$$
\Delta P_{\mathrm{t}}=\Delta P_{\mathrm{L}}+\Delta P_{\mathrm{A}},
$$

where $\Delta P_{\mathrm{t}}$ is the gross pressure variation; $\Delta P_{\mathrm{A}}$ is the frictional pressure loss; and $\Delta P_{\mathrm{L}}$ is the local pressure loss, which can be expressed as

$$
\Delta P_{\mathrm{L}}=\kappa \rho v^{2} / 2
$$

where $\kappa$ is a loss coefficient, and $v$ is the mean port velocity.

The frictional pressure loss can be written as

$$
\Delta P_{\mathrm{A}}=\frac{f L \rho v^{2}}{2 D_{\mathrm{e}}}
$$

where $L$ is the channel length, and $f$ represents the friction factor (Huang et al., 2008; 2013), which can be expressed as

$$
f=1.12(\operatorname{Re})^{-0.36}\left(\frac{1}{D_{\mathrm{e}}}\right)^{-0.65}\left(\frac{t}{D_{\mathrm{e}}}\right)^{-0.17}
$$

The hydraulic diameter, $D_{\mathrm{e}}$, in different sections along the channel can be expressed as

$$
D_{\mathrm{e}}=\frac{4 A_{\mathrm{s}}}{P_{1}}=4 \frac{a b-(n+1) b t-2 a t}{2\{[a-(n+1) t]+n(b-t)\}} .
$$

In Eqs. (12)-(15), $A_{\mathrm{s}}$ is the flow area of the channel; $P_{1}$ is the wetted perimeter of the channel; $t$ is 
the fin thickness; $a$ is the channel width; $b$ is the channel height; and $R e$ is the Reynolds number, which can be expressed as

$$
R e=\frac{D_{\mathrm{e}} M}{\lambda A_{\mathrm{e}}}
$$

For a single channel, the height $H$ is $0.1 \mathrm{~m}$, the width $W$ is $0.003 \mathrm{~m}$, the wetted perimeter $P_{1}$ is $0.206 \mathrm{~m}$, the area $\left(A_{\mathrm{s}}=A_{\mathrm{e}}\right.$, where $A_{\mathrm{e}}$ is the sectional area of channel) is $3 \times 10^{-4} \mathrm{~m}^{2}$, the fluid density $\rho$ is $1 \times 10^{3} \mathrm{~kg} / \mathrm{m}^{3}$, the fluid viscosity $\lambda$ is $8.545 \times 10^{-4} \mathrm{~Pa} \cdot \mathrm{s}$ at a temperature of $300 \mathrm{~K}$, the velocity at the inlet is $1 \mathrm{~m} / \mathrm{s}$, and then the mass flow rate of fluid $(M)$ is $0.3 \mathrm{~kg} / \mathrm{m}^{3}$. According to the above parameters, $R e$ can be calculated as $\operatorname{Re}=\frac{D_{\mathrm{e}} M}{\lambda A_{\mathrm{e}}}=6817$.

\section{Mesh and boundary conditions}

The process of fluid flow and heat transfer in channels is simulated. First, the inlet and outlet of channels, turning points of fins, and neighboring points are treated by grid refinement. The grid model is shown in Fig. 2.

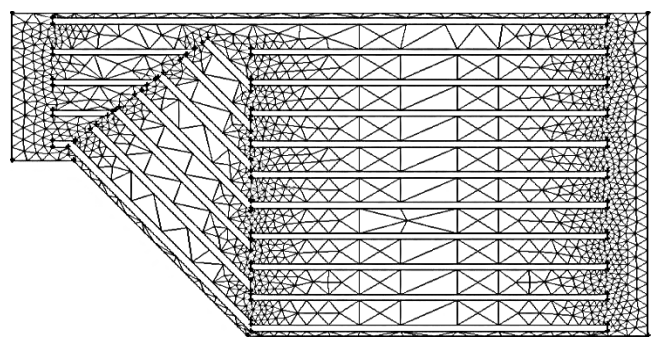

Fig. 2 Mesh generation of fin structure in channels under a single layer

To illustrate the relationship between grid convergence and mass and energy balance, the grid convergence analysis, mass and energy balance checks of plate-fin heat exchanger are investigated in this study.

1. Grid convergence analysis

Grid convergence analysis is proposed for the CFD analysis for estimating the calculation error caused by grid scale. For the analysis of grid convergence, a fin arrangement $(5: 11: 11)$ is chosen. Six cases with grid numbers of 11912, 39344, 2120, 207998, 90738 , and 54496 (from case 1 to case 6) are analyzed. We import the meshing results to Fluent (Al-Waked et al., 2013), and then calculate the results and error of dynamic pressure, velocity, and temperature.

The dynamic pressure and pressure difference under six kinds of mesh grid are given in Fig. 3. In Fig. 3a, the pressure difference among six kinds of mesh grid is shown. From Fig. 3a, we can find that, in most cases, the pressure difference among three cases is within the range of -0.2 to $0.1 \mathrm{~Pa}$. In Fig. 3a the minimum value of dynamic pressure difference is $0.0514 \mathrm{~Pa}$. The dynamic pressure difference demonstrates the mesh grid can cause increased dynamic pressure difference, while, for most cases the difference is little at each monitoring position. In Fig. 3b, the dynamic pressure of six kinds of mesh grid at the outlet is shown. From Fig. 3b, the dynamic pressure curves of the three cases are basically identical with just a little change at each monitoring position. For the whole monitoring positions, the maximum dynamic pressure is nearly $1.34 \mathrm{~Pa}$. From the above analysis, we can find that the impact on dynamic pressure of a difference in mesh grid is little.

The velocity distribution and velocity difference under six kinds of mesh grid are shown in Fig. 4. In Fig. $4 \mathrm{a}$, the velocity difference under six kinds of mesh grid is in the range of -0.2 to $0.2 \mathrm{~m} / \mathrm{s}$. In Fig. $4 \mathrm{a}$, the maximum value of velocity difference reaches $0.25 \mathrm{~m} / \mathrm{s}$, while the minimum value of velocity difference is $0.0468 \mathrm{~m} / \mathrm{s}$. From Fig. 4a, the velocity difference is little for most cases at each monitoring position. The velocity distribution at the outlet of the exchanger under six kinds of mesh grid is shown in Fig. 4b. In Fig. 4b, we can find that the velocity has a little increase at each monitoring position. At each motoring position, the velocity distribution is almost identical. These results on velocity variation with six kinds of mesh grid also show that the velocity at the outlet of the exchanger has little variation at each position.

The temperature distribution and temperature difference under six kinds of mesh grid are shown in Fig. 5. In Fig. 5a, the temperature difference among six cases is in the range of $-7 \times 10^{-3}$ to $7 \times 10^{-3} \mathrm{~K}$. The 


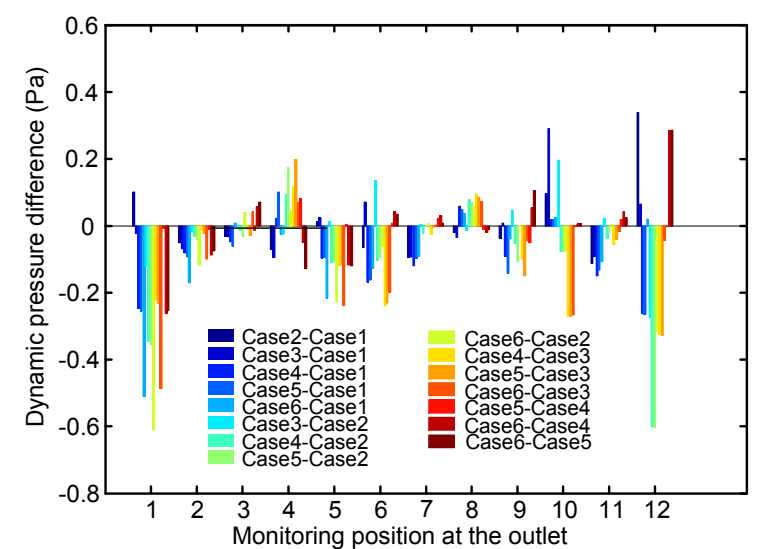

(a)

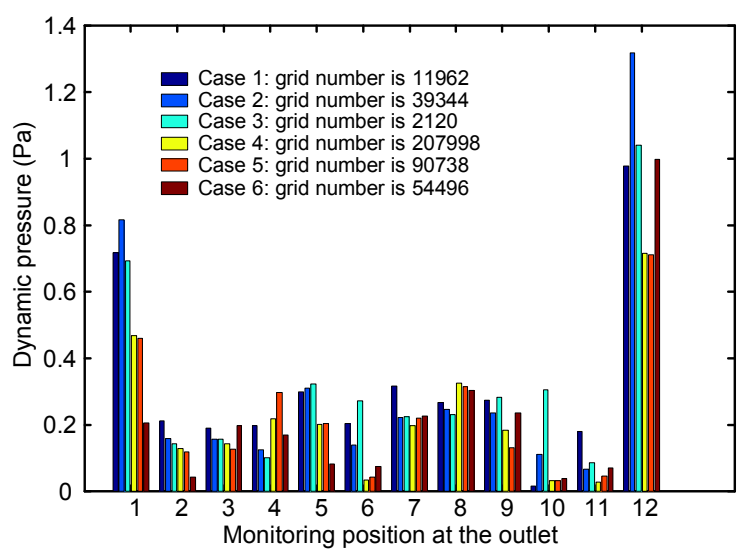

(b)

Fig. 3 Dynamic pressure and pressure difference at the outlet under six kinds of mesh grid (a) Pressure difference among six cases; (b) Dynamic pressure distribution of plate-fin heat exchanger

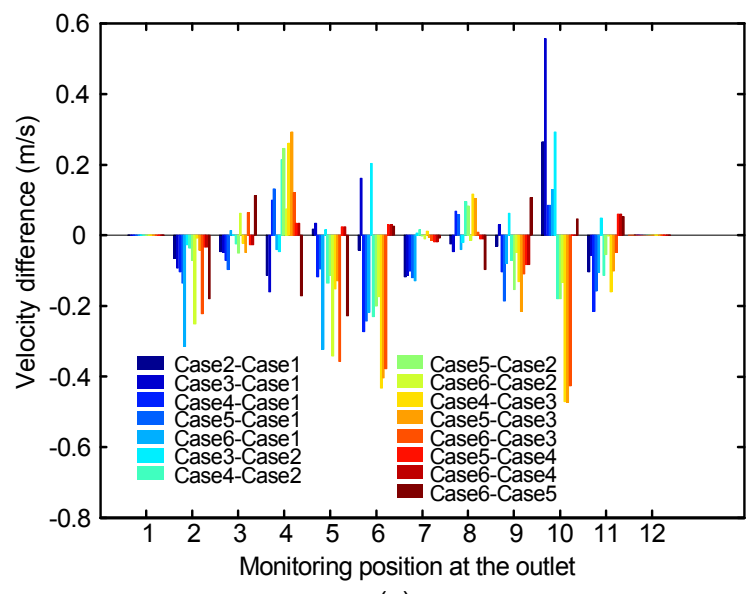

(a)

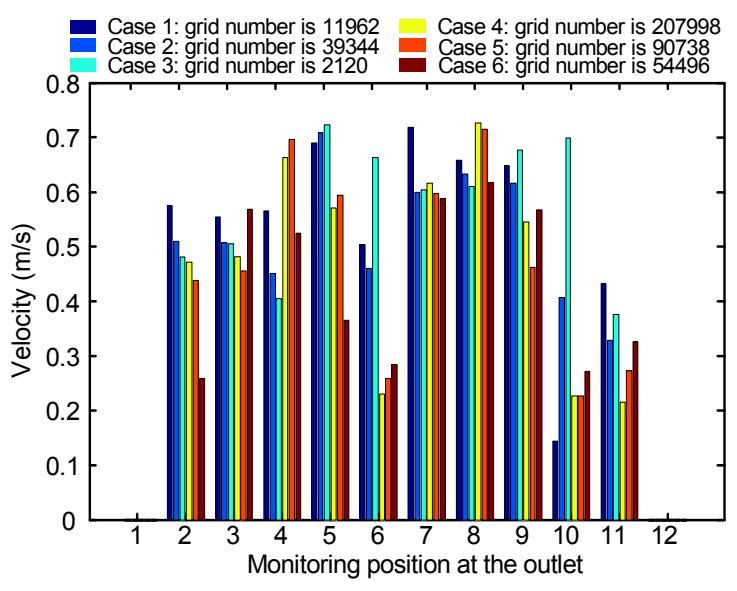

(b)

Fig. 4 Velocity distribution and velocity difference at outlet under six kinds of mesh grid (a) Velocity difference among six cases; (b) Velocity distribution of plate-fin heat exchanger

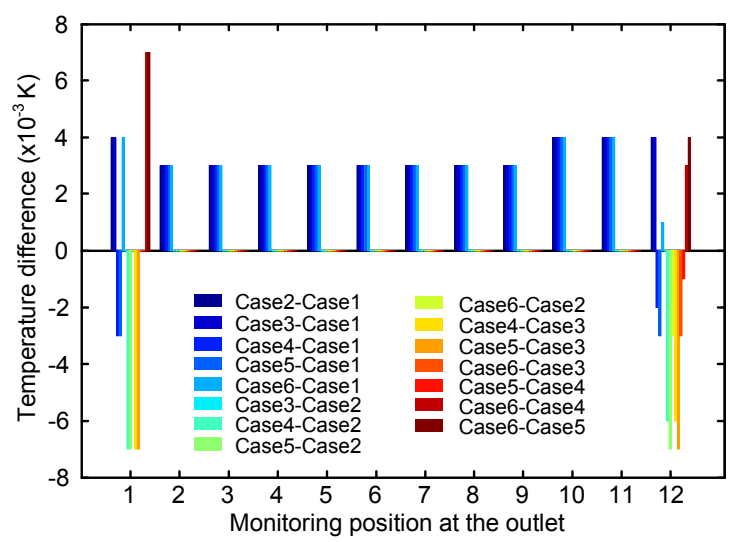

(a)

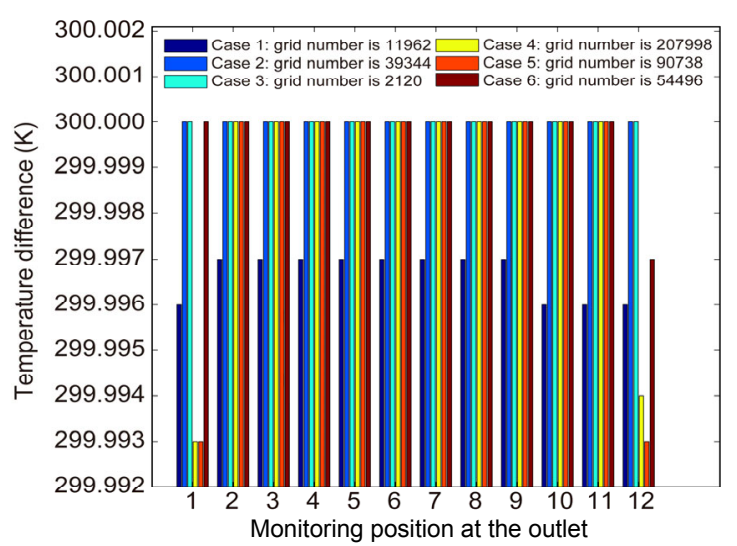

(b)

Fig. 5 Temperature distribution and temperature difference at outlet under six kinds of mesh grid (a) Temperature difference among six cases; (b) Temperature distribution of plate-fin heat exchanger 
temperature difference among six kinds of mesh grid is zero for some cases at each monitoring position. The temperature distribution at the outlet of the exchanger under six kinds of mesh grid is shown in Fig. 5b. From Fig. 5b, we can find that the temperature at the outlet in the three cases shows such little variation that cannot be found. From the above analysis, we can find that for cases of greater grid refinement (finer mesh grid), the difference still exists and cannot be eliminated, but for temperature distribution, the difference caused by grid refinement can be ignored.

\section{Mass balance check}

To demonstrate mass balance caused by different mesh grids, the mass balance check of three kinds of mesh grid is given in Table 1. The spacing of the mesh is $0.5,1$, and 5 , and from Table 1 , we can find that the mass flux has no difference. Thus, the spacing of the mesh grid has no effect on mass flux.

Table 1 Flux variation between inlet and outlet in platefin heat exchanger

\begin{tabular}{cccc}
\hline Case & $\begin{array}{c}\text { Inlet mass } \\
\text { flux }(\mathrm{kg} / \mathrm{s})\end{array}$ & $\begin{array}{c}\text { Outlet } \\
\text { mass flux } \\
(\mathrm{kg} / \mathrm{s})\end{array}$ & $\begin{array}{c}\text { Mass flux } \\
\text { variation } \\
(\mathrm{kg} / \mathrm{s})\end{array}$ \\
\hline $\begin{array}{c}\text { Case 1 } \\
\text { (spacing=1) }\end{array}$ & 30.625006 & 30.625 & $5.72 \times 10^{-6}$ \\
$\begin{array}{c}\text { Case 2 } \\
\text { (spacing=0.5) }\end{array}$ & 30.625008 & 30.625008 & 0 \\
$\begin{array}{c}\text { Case 3 } \\
\text { (spacing=5) }\end{array}$ & 30.625 & 30.624996 & $3.81 \times 10^{-6}$ \\
\hline
\end{tabular}

To illustrate the flux variation with different kinds of fin arrangement, the mass balance check is shown in Table 2 for seven kinds of fin arrangement. As shown in Table 2, the mass flux between inlet and outlet has no change without considering phase change.

Table 2 Mass balance check between inlet and outlet under different fin arrangements (grid spacing=1)

\begin{tabular}{cclc}
\hline Case & Inlet $(\mathrm{kg} / \mathrm{s})$ & Outlet $(\mathrm{kg} / \mathrm{s})$ & $\begin{array}{c}\text { Mass variation } \\
\left(\times 10^{-7} \mathrm{~kg} / \mathrm{s}\right)\end{array}$ \\
\hline 1 & 6.125 & 6.124999 & 4.768 \\
2 & 6.125 & 6.1249986 & 14.305 \\
3 & 6.125 & 6.1249995 & 4.768 \\
4 & 6.125 & 6.124999 & 9.537 \\
5 & 6.125 & 6.125 & 4.768 \\
6 & 6.125 & 6.125 & 4.768 \\
7 & 6.125 & 6.124999 & 4.768 \\
\hline
\end{tabular}

\section{Energy balance check}

The energy balance between inlet and outlet of the exchanger under different grid spacing is shown in Table 3. It can be concluded from Table 3 that the energy has no significant change for the three kinds of grid spacing. However, heat transfer is influenced by grid spacing. In Table 3, heat transfer increases when grid space decreases, instead, energy has slight change.

Table 3 Energy balance check between inlet and outlet in plate-fin heat exchanger

\begin{tabular}{ccccc}
\hline Case & $\begin{array}{c}\text { Inlet } \\
\text { energy } \\
(\mathrm{W})\end{array}$ & $\begin{array}{c}\text { Outlet } \\
\text { energy } \\
(\mathrm{W})\end{array}$ & $\begin{array}{c}\text { Heat } \\
\text { transfer } \\
(\mathrm{W})\end{array}$ & $\begin{array}{c}\text { Energy } \\
\text { variation } \\
(\mathrm{W})\end{array}$ \\
\hline $\begin{array}{l}\text { Case 1 } \\
\text { (spacing=1) }\end{array}$ & 57020.578 & 57019.891 & 0.6875 & -0.0005 \\
$\begin{array}{l}\text { Case 2 } \\
\text { (spacing=0.5) }\end{array}$ & 57019.879 & 57022.219 & 2.34 & -4.68 \\
$\begin{array}{l}\text { Case 3 } \\
\text { (spacing=5) }\end{array}$ & 57020.539 & 56923.176 & 97.363281 & $-2.8 \times 10^{-4}$ \\
\hline
\end{tabular}

Similarly, in order to examine the influence on heat transfer of fin arrangements, the energy balance check for seven conditions is shown in Table 4.

Table 4 Energy balance check between inlet and outlet under seven kinds of fin arrangement (grid spacing=1)

\begin{tabular}{ccccc}
\hline Case & $\begin{array}{c}\text { Inlet } \\
\text { energy } \\
(\mathrm{W})\end{array}$ & $\begin{array}{c}\text { Outlet } \\
\text { energy } \\
(\mathrm{W})\end{array}$ & $\begin{array}{c}\text { Heat } \\
\text { transfer } \\
(\mathrm{W})\end{array}$ & $\begin{array}{c}\text { Energy } \\
\text { variation } \\
(\mathrm{W})\end{array}$ \\
\hline 1 & 11408.03 & 3548.15 & 7859.87 & 0.001 \\
2 & 11408.12 & 503.43 & 10904.7 & -0.0001 \\
3 & 11408.31 & 5290.88 & 6117.43 & -0.0003 \\
4 & 11408.31 & 1287.4 & 10120.91 & 0.001 \\
5 & 11408.35 & 494.41 & 10913.94 & -0.0043 \\
6 & 11408.30 & 3896.13 & 7512.16 & 0.0019 \\
7 & 11408.21 & 3561.78 & 7846.43 & 0.0001 \\
\hline
\end{tabular}

It can be concluded from Table 4 that energy does not change with different fin arrangements, and therefore the energy balance is satisfied. From Table 4, we also find that heat transfer varies with different fin arrangements so the heat transfer of the whole exchanger can be influenced.

The computational domains in this study are the inlet, diversion, and heat exchange sections (Fig. 6). The fluid flow and temperature variation under different fin arrangements are analyzed. 


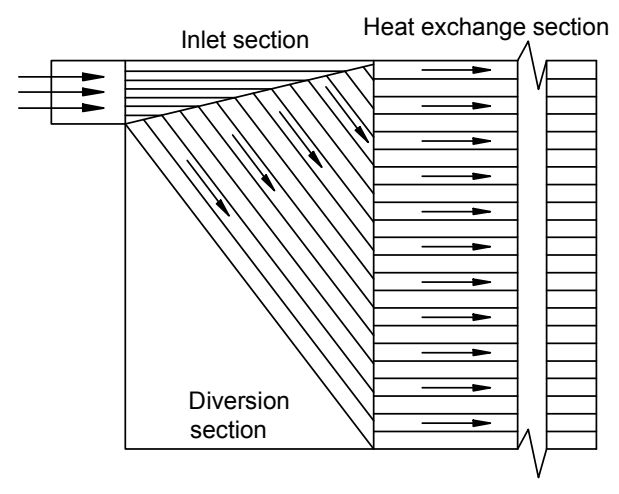

Fig. 6 Computational domain of the plate-fin heat exchanger

\section{Boundary conditions}

The fluid medium is water and assumed to be incompressible, and fins and parting plates are made of 300-O aluminum. Fluid flows into the exchanger from the inlet section. The fluid is single phase flow and the velocity is $1 \mathrm{~m} / \mathrm{s}$. The inlet temperature is $300 \mathrm{~K}$. The outlet conditions include the pressure outlet.

A non-slip boundary condition is adopted in this study. Heat transfer between the wall and the atmosphere is not considered. The variation of heat exchange coefficient with temperature is also ignored. Then, a comprehensive heat exchange coefficient can be used to calculate the heat transfer according the material of the exchanger considering the fin and the separate plate as a whole.

The equation of flow field is solved by the method of pressure-velocity coupling, a $k-\varepsilon$ turbulence model is used for fluid flow in the turbulence areas, and a finite volume method is used for solution of the fluid control equation. We adopt a second-order upwind scheme for solution of the energy and momentum equations on the basis that the residual error of physical quantities in the control module areas $\varepsilon<0.001$. For convergence of residual errors, the under-relaxation factor of momentum is 0.3 , while other parameters have their default values. Since the computation domain of plate-fin heat exchange is usually large, the partition method is adopted for mesh generation, and contact areas in different sections of fin structure are treated by mesh refinement. We took the flow velocity as $1 \mathrm{~m} / \mathrm{s}$ at the inlet. Four monitoring positions (L1, L2, L3, L4) shown in Fig. 1 in different sections of the exchanger are selected for fluid flow and temperature distribution.

Fluid flow in the channels is calculated according to fin arrangement in four sections. Assuming fluid flows in the direction of the $x$ axis, then flow rate in the directions of the $y$ and $z$ axes should meet

$$
v_{y}=v_{z}=0
$$

Temperature in the starting position of fins in the inlet section should be consistent with that of the fluid. The external wall of the exchanger is insulated; the direction of fin heat conduction is orthogonal to the direction of fluid flow in channels. On this basis, the temperature variation of fluid in the other two directions and temperature variation of separating plates should satisfy

$$
\frac{\partial T_{\mathrm{f}}}{\partial x}=\frac{\partial T_{\mathrm{f}}}{\partial z}=0, \quad \frac{\partial T_{\mathrm{w}}}{\partial x}=\frac{\partial T_{\mathrm{w}}}{\partial z}=0,
$$

where $T_{\mathrm{f}}$ is the average temperature of fins, and $T_{\mathrm{w}}$ is the average temperature of the wall.

\section{Results and discussion}

To determine fluid distribution at the outlet, various monitoring points are selected, and mean square errors (MSE) of fluid parameters at the points are calculated. A large square error implies a high dispersion degree of parameters at the point, and poor distribution of fluid parameters at the outlet. Mean values and MSE of parameters at the points can be calculated according to

$$
\begin{gathered}
\zeta=\frac{1}{M-2} \sum_{i=2}^{M-1} f_{i}, \\
\xi=\sqrt{\frac{\sum_{j=1}^{N}\left(f_{j}-\frac{1}{M} \sum_{j=1}^{M} f_{j}\right)^{2}}{N}},
\end{gathered}
$$

where $\zeta$ is the mean value of the parameter; $\xi$ is MSE of the parameter; and $f_{i}$ or $f_{j}$ is the measured value of the parameter at monitoring points. 
Eighteen types of fin arrangements are used for analyzing fluid flow and heat transfer in different sections at the inlet. The number of fins in different sections at the inlet, the spacing of fins, and the temperature at the inlet of plate-fin heat exchanger are listed in Tables 5 and 6.

\subsection{Analysis of fluid flow}

Fluid flow in the plate-fin heat exchanger is analyzed under the seven modes of fin arrangement as listed in Table 5. The analysis model as shown in Fig. 1 is created, in which straight fins are used and fluid flows from the left to right in the exchanger. For spacing, two fin arrangements, 3:8:11 and 5:8:11, are taken and the effects of the arrangements on fluid velocity are analyzed. The results of a simulation analysis on flow rate are given in Figs. 7 and 8. These show that, in the cases of three fins (case 1) and five fins (case 2) in the inlet section, the mean flow rate is $0.869 \mathrm{~m} / \mathrm{s}$ and $0.836 \mathrm{~m} / \mathrm{s}$, and the square error is 0.773 and 0.709 , respectively. The flow rate of fluid increases by $3.95 \%$, and the square error increases by $9.03 \%$, which indicates that a dense fin arrangement can improve the fluid distribution in different channels.

Fluid mean flow rate in various monitoring points under seven fin arrangements is shown in Fig. 9. It can be seen that the mean flow rate decreases progressively in the flow direction. This is mainly because the fin has a certain thickness, and more fins will take up more space and lead to an increase in the flow rate of fluid in the channels.

The distribution of fluid turbulence intensity in exchangers with different fin arrangements is shown in Figs. 10 and 11. It can be seen that turbulence intensity varies insignificantly with fin arrangement, the maximum of turbulence intensity appears at the inlet, and the intensity decreases gradually in the flow direction. In Fig. 10, the mean turbulence intensity in

Table 6 Fin arrangements in different sections

\begin{tabular}{ccc}
\hline \multicolumn{3}{c}{ Number of fins } \\
\hline $\begin{array}{c}\text { Inlet } \\
\text { section }\end{array}$ & $\begin{array}{c}\text { Diversion } \\
\text { section }\end{array}$ & $\begin{array}{c}\text { Exchanging } \\
\text { section }\end{array}$ \\
\hline 3 & 4 & 6 \\
5 & 6 & 8 \\
7 & 8 & 11 \\
9 & 10 & 13 \\
- & 12 & 16 \\
- & 14 & 18 \\
- & 16 & 21 \\
\hline
\end{tabular}

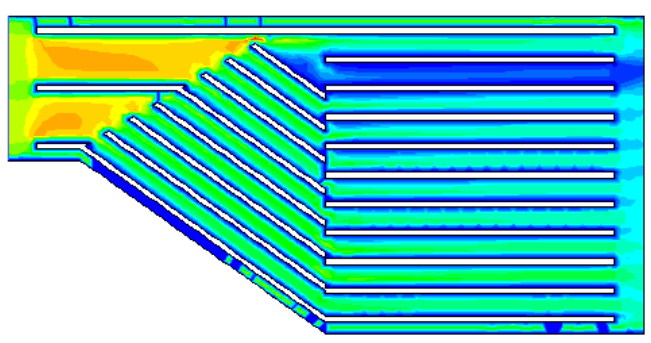

Fig. 7 Simulation on fluid velocity distribution (case 1)

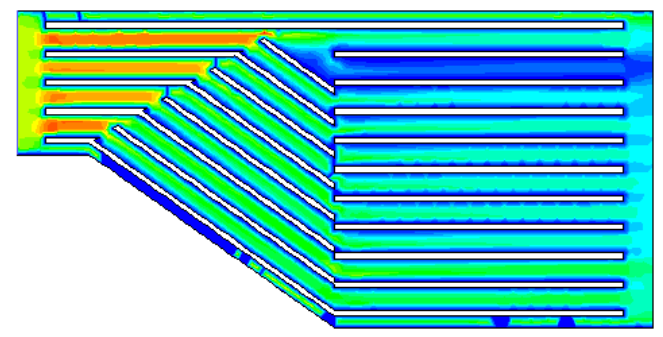

Fig. 8 Simulation on fluid velocity distribution (case 2)

Table 5 Fin arrangements and inlet temperature

\begin{tabular}{|c|c|c|c|c|c|c|c|c|}
\hline \multirow[b]{2}{*}{ Case } & \multicolumn{3}{|c|}{ Number of fins } & \multirow{2}{*}{$\begin{array}{c}\text { Fin } \\
\text { thickness, } \\
t(\mathrm{~mm})\end{array}$} & \multicolumn{3}{|c|}{ Spacing of fins, $D(\mathrm{~mm})$} & \multirow{2}{*}{$\begin{array}{c}\text { Inlet tem- } \\
\text { perature, } \\
T(\mathrm{~K})\end{array}$} \\
\hline & $\begin{array}{c}\text { Inlet } \\
\text { section }\end{array}$ & $\begin{array}{c}\text { Direction } \\
\text { section }\end{array}$ & $\begin{array}{c}\text { Exchanging } \\
\text { section }\end{array}$ & & $\begin{array}{c}\text { Inlet } \\
\text { section }\end{array}$ & $\begin{array}{c}\text { Diversion } \\
\text { section }\end{array}$ & $\begin{array}{c}\text { Heat exchange } \\
\text { section }\end{array}$ & \\
\hline 1 & 3 & 8 & 11 & 0.2 & 0.25 & 0.5 & 0.5 & 300 \\
\hline 2 & 5 & 8 & 11 & 0.2 & 0.5 & 0.5 & 0.5 & 300 \\
\hline 3 & 5 & 8 & 21 & 0.2 & 0.5 & 0.5 & 0.25 & 300 \\
\hline 4 & 5 & 4 & 11 & 0.2 & 0.5 & 1 & 0.5 & 300 \\
\hline 5 & 5 & 16 & 11 & 0.2 & 0.5 & 0.25 & 0.5 & 300 \\
\hline 6 & 9 & 8 & 11 & 0.2 & 1 & 0.5 & 0.5 & 300 \\
\hline 7 & 5 & 8 & 6 & 0.2 & 0.5 & 0.5 & 1 & 300 \\
\hline
\end{tabular}


various channels is $0.206 \%$, while in Fig. 11 the mean value is $0.147 \%$.

Fig. 12 gives the mean turbulence intensity of fluid at different monitoring positions under different fin arrangements and shows that under the seven modes of fin arrangement the turbulence intensity decreases gradually in the flow direction, and the maximum intensity at the inlet is $92.06 \%$ different from that at the outlet.

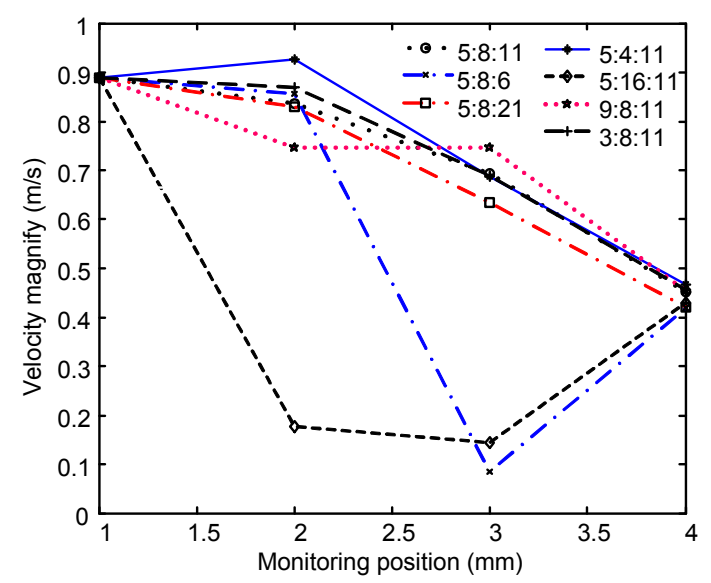

Fig. 9 Flow velocity distribution in the inlet section with different number of fins

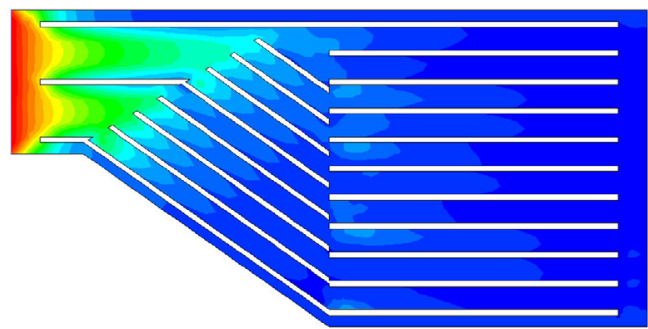

Fig. 10 Simulation on turbulent intensity distribution (case 1)

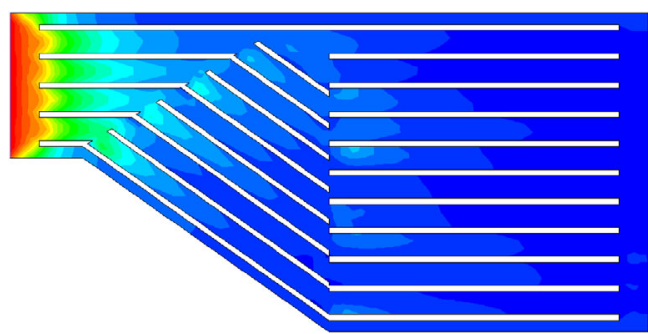

Fig. 11 Simulation on turbulent intensity distribution (case 2)

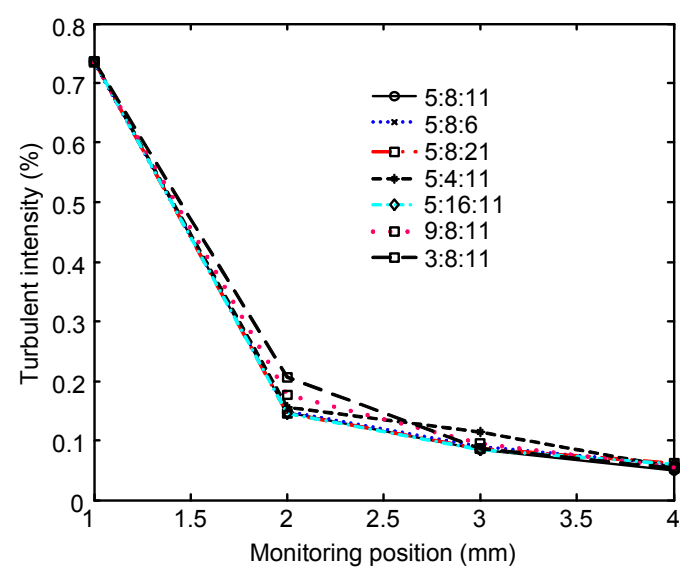

Fig. 12 Turbulence intensity in the inlet section with different number of fins

\subsection{Analysis of temperature distribution}

As the main heat exchanging units of a plate-fin exchanger, fins play a key role in heat transfer. Distribution of fluid temperature is determined by analysis of the heat transfer performance of fins in the flow direction and the destructive effect of fins on the heat transfer boundary layer of the fluid. The temperature field at the inlet of the exchanger shown in Fig. 1 is analyzed. Based on fin arrangements of $3: 8: 11$ and $5: 8: 11$, the results of simulation analysis on the inlet temperature field are shown in Figs. 13 and 14. The main heat exchanging units of a plate-fin exchanger are fins and parting plates, while the main structure that can damage the thermal boundary layer is the fin. This is mainly because the number of fins varies in different sections, leading to an increase in turbulent dissipation at the contact positions. In addition, heat conduction by fins in the flow direction will affect the distribution of temperature inside the exchanger.

Comparing Fig. 13 with Fig. 14 shows that, under the above-mentioned fin arrangements, the density of fin arrangement will affect the temperature distribution of the fluid; a dense arrangement will lead to even temperature distribution in the exchanging section and significant temperature variation in the flow direction when the flow rate at the inlet remains unchanged. The less the spacing of fins, the more significantly fluid temperature varies at the contact positions of fins. Fig. 15 shows the mean temperature of the fluid at various monitoring points under different fin arrangements; under the given fluid 
conditions and seven modes of fin arrangement, the fluid temperature decreases gradually in the flow direction; in the case of the 3:8:11 arrangement, fluid temperature at monitoring position L1 is $0.118 \%$, $0.328 \%$, and $0.430 \%$ higher than that at L2, L3, and L4, respectively; in the case of the 5:8:11 arrangement, the fluid temperature at monitoring position $\mathrm{L} 1$ is $0.163 \%, 0.349 \%$, and $0.432 \%$ higher than that at L2, L3, and L4, respectively. The main reasons are that a dense fin arrangement will improve the evenness of fluid distribution in channels that is directly related to the temperature of fluid, and the secondary heat transfer by fins will accelerate the temperature exchange between cold and hot fluids; in addition,

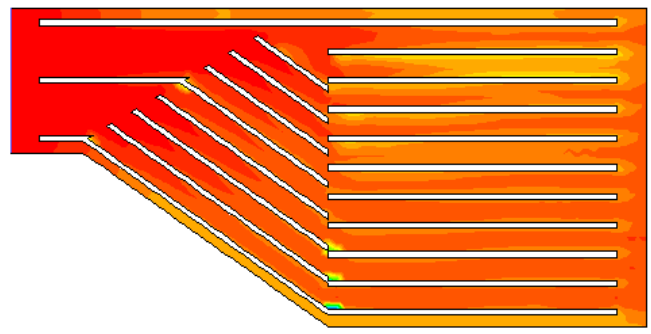

Fig. 13 Simulation on temperature distribution (case 1)

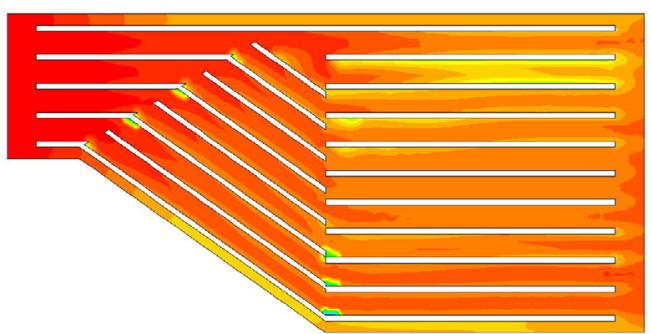

Fig. 14 Simulation on temperature distribution (case 2)

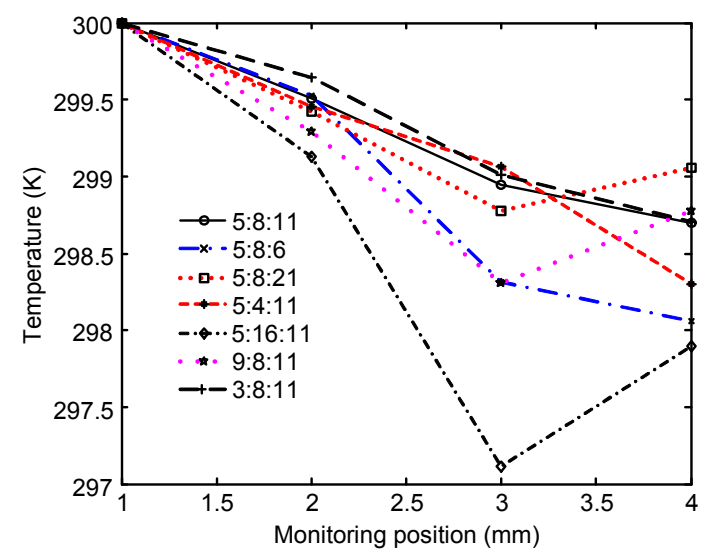

Fig. 15 Distribution of fluid temperature in different sections turbulence at the points of contact will damage the heat transfer boundary layer of the fluid, intensify convective heat transfer of fluid, and improve heat transfer of the exchanger.

\subsection{Comparison of fin arrangements}

The effects of different fin arrangements at the inlet of exchange on fluid parameters at the outlet are analyzed. The mean values of fluid parameters at the outlet are calculated for 18 kinds of fin arrangement. These are listed for the inlet, diversion, and exchanging sections in Table 7, for fluid velocity, pressure, and temperature. With increase of fin number in the three sections, the maximum pressure is $0.195 \mathrm{MPa}$ with a temperature of $298.58 \mathrm{~K}$ when the fin number is 9 in the inlet section. The minimum pressure is $0.166 \mathrm{MPa}$ with a temperature of $298.47 \mathrm{~K}$ when the fin number is 3 .

For the diversion section, the minimum mean value of temperature at the outlet occurs when the fin number is 16 while the mean value of pressure is $0.196 \mathrm{MPa}$. This is the maximum value among the 18 results. In addition, the minimum value of pressure is $0.144 \mathrm{MPa}$ which occurs when the fin number in the diversion section is 6 while the outlet temperature is near $300 \mathrm{~K}$.

For the heat exchange section, the maximum pressure is $0.166 \mathrm{MPa}$ with a minimum temperature of $298.47 \mathrm{~K}$ when the fin number is 11 . The minimum pressure is $0.145 \mathrm{MPa}$ with a maximum temperature near $300 \mathrm{~K}$ when the fin number is 16 .

The above results demonstrate that fin arrangement in diversion sections has a more significant effect on fluid distribution and heat transfer in comparison with the inlet and heat exchange sections. An appropriate fin number can not only reduce the pressure drop but also increase heat transfer efficiency.

The main reason is that the thickness of the fins in channels leads to disturbance of fluid flow in the channels. This disturbance mainly occurs at the contact points in various sections of the inlet part, and at the inlet and outlet, which may change the type of fluid flow and intensify turbulence. As the fluid meets the condition of continuity, its flow rate varies little at the inlet and outlet. In addition, with increase in fin number, the width of channels is decreased, fluid flow is accelerated, and fluid turbulence becomes more obvious in the case of a change in the flow interface. 
Table 7 Parameters variation at the outlet caused by fin arrangements

\begin{tabular}{|c|c|c|c|c|c|c|c|}
\hline \multirow{2}{*}{ Section } & \multirow{2}{*}{$\begin{array}{c}\text { Number } \\
\text { of fins }\end{array}$} & \multicolumn{3}{|c|}{ Mean value } & \multicolumn{3}{|c|}{ MSE } \\
\hline & & Velocity $(\mathrm{m} / \mathrm{s})$ & Pressure (MPa) & Temperature (K) & Velocity & Pressure & Temperature \\
\hline \multirow{4}{*}{$\begin{array}{c}\text { Inlet } \\
\text { section }\end{array}$} & 3 & 0.457 & 0.166 & 298.47 & 0.321 & 0.096 & 14.064 \\
\hline & 5 & 0.451 & 0.166 & 298.47 & 0.303 & 0.072 & 13.321 \\
\hline & 7 & 0.413 & 0.176 & 299.99 & 0.428 & 0.141 & 1.138 \\
\hline & 9 & 0.454 & 0.195 & 298.58 & 0.357 & 0.069 & 11.935 \\
\hline \multirow{7}{*}{$\begin{array}{l}\text { Diversion } \\
\text { section }\end{array}$} & 4 & 0.467 & 0.176 & 297.95 & 0.452 & 0.190 & 18.236 \\
\hline & 6 & 0.414 & 0.144 & 299.99 & 0.291 & 0.133 & 0.785 \\
\hline & 8 & 0.451 & 0.166 & 298.47 & 0.303 & 0.073 & 13.321 \\
\hline & 10 & 0.419 & 0.155 & 299.99 & 0.328 & 0.149 & 0.616 \\
\hline & 12 & 0.422 & 0.169 & 299.99 & 0.375 & 0.168 & 0.861 \\
\hline & 14 & 0.419 & 0.164 & 299.99 & 0.248 & 0.149 & 0.843 \\
\hline & 16 & 0.429 & 0.196 & 297.66 & 0.379 & 0.192 & 27.640 \\
\hline \multirow{7}{*}{$\begin{array}{l}\text { Heat exchange } \\
\text { section }\end{array}$} & 6 & 0.421 & 0.153 & 298.74 & 0.304 & 0.142 & 11.360 \\
\hline & 8 & 0.424 & 0.148 & 299.99 & 0.249 & 0.130 & 0.453 \\
\hline & 11 & 0.451 & 0.166 & 298.47 & 0.303 & 0.073 & 13.321 \\
\hline & 13 & 0.471 & 0.162 & 299.99 & 0.306 & 0.142 & 0.355 \\
\hline & 16 & 0.402 & 0.145 & 299.99 & 0.044 & 0.105 & 0.814 \\
\hline & 18 & 0.401 & 0.151 & 299.99 & 0.295 & 0.144 & 0.453 \\
\hline & 21 & 0.418 & 0.166 & 299.99 & 0.289 & 0.034 & 0.699 \\
\hline
\end{tabular}

\subsection{Results validation}

The fluid flow and temperature variation caused by different fin arrangements in plate-fin heat exchanger was investigated using Fluent. The evaluating indicator for performance, i.e., the heat transfer and pressure ratio, $Q_{P}$, is proposed to choose the best fin arrangement. Generally, the higher values of $Q_{P}$ mean better heat transfer. $Q_{P}$ is expressed as

$$
\begin{aligned}
Q_{P} & =\frac{\Delta Q_{\text {avg }}}{\Delta P_{\text {avg }}}=\frac{\left[\Delta Q_{\text {avg }}\right]_{\text {out }}-\left[\Delta Q_{\text {avg }}\right]_{\text {in }}}{\left[\Delta P_{\text {avg }}\right]_{\text {out }}-\left[\Delta P_{\text {avg }}\right]_{\text {in }}} \\
& =\frac{\left[\frac{1}{m_{\text {total }}} \sum_{i=1}^{m_{\text {total }}} Q_{i}\right]-\left[\frac{1}{n_{\text {total }}} \sum_{j=1}^{n_{\text {total }}} Q_{j}\right]}{\left[\frac{1}{s_{\text {total }}} \sum_{k=1}^{s_{\text {total }}} P_{k}\right]-\left[\frac{1}{t_{\text {total }}} \sum_{l=1}^{t_{\text {toat }}} P_{l}\right]}
\end{aligned}
$$

where $m_{\text {total }}$ and $n_{\text {total }}$ is the number of the outlet and inlet heat flux; $s_{\text {total }}$ and $t_{\text {total }}$ is the number of the outlet and inlet dynamic pressure, respectively; $Q_{i}$ is the inlet dynamic pressure at point $i ; P_{k}$ is the dynamic pressure at point $k$; the subscript avg represents the average value; and the subscripts out and in represent the outlet and inlet, respectively.
From Table 8 we can conclude that the three parameters including heat transfer, dynamic pressure, and heat transfer and pressure ratio vary with different fin arrangements. The variation of the three parameters is shown in Figs. 16-18.

Table 8 Heat transfer, dynamic pressure, and heat transfer and pressure ratio under different fin arrangements

\begin{tabular}{crrl}
\hline Case & \multicolumn{1}{c}{$Q_{\text {avg }}$} & $P_{\text {avg }}$ & \multicolumn{1}{c}{$Q_{P}$} \\
\hline 1 & 7846.43 & 0.446 & 17592.89 \\
2 & 10904.70 & 0.446 & 24450 \\
3 & 6117.43 & 0.459 & 13327.73 \\
4 & 10120.91 & 0.436 & 23213.1 \\
5 & 10913.94 & 0.416 & 26235.43 \\
6 & 7512.16 & 0.417 & 18014.77 \\
7 & 7859.87 & 0.446 & 17623.03 \\
\hline
\end{tabular}

\subsection{Analysis of wall function and $Y$ plus}

As shown in Fig. 1, the plate-fin heat exchanger layer of fluid flow can be generated. Therefore, the boundary-layer flow near the wall should be considered. The standard $k-\varepsilon$ model was adopted to analyze turbulent flow in the fully developed turbulent area. A wall function was used in this study. Two methods of 
analyzing fluid flow on walls were adopted: (a) a modified $k-\varepsilon$ model to calculate fluid viscosity near the wall; (b) semi-empirical method (wall function) to

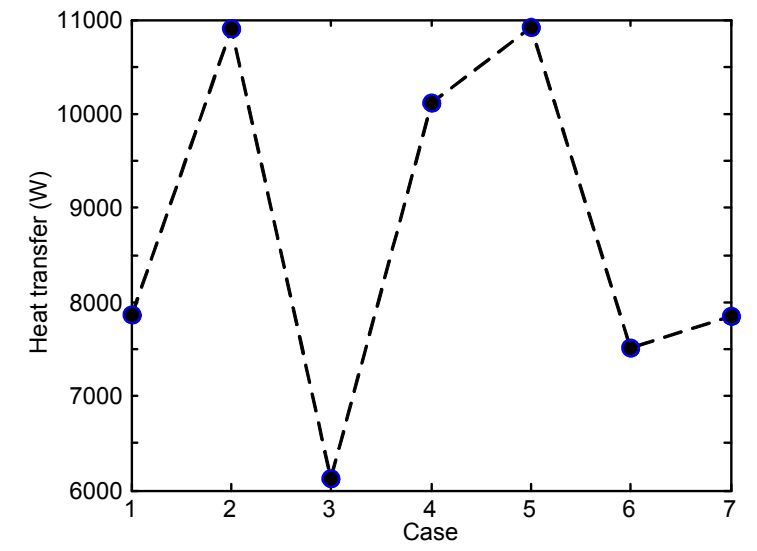

Fig. 16 Heat transfer under seven kinds of fin arrangement

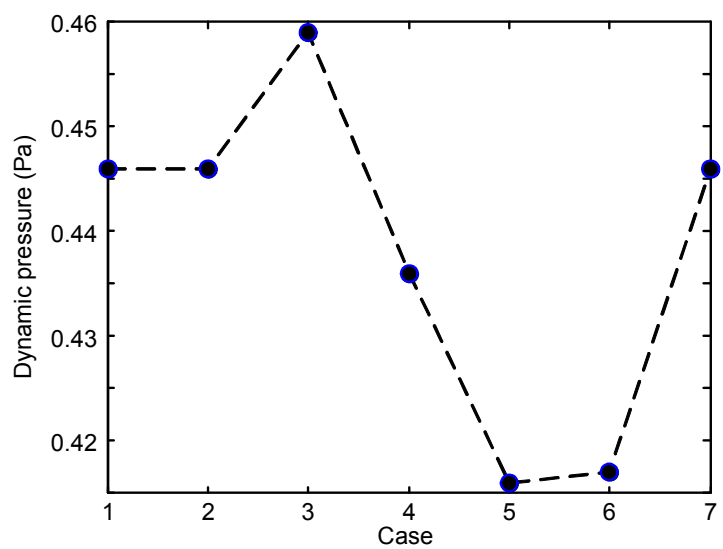

Fig. 17 Dynamic pressure under seven kinds of fin arrangement

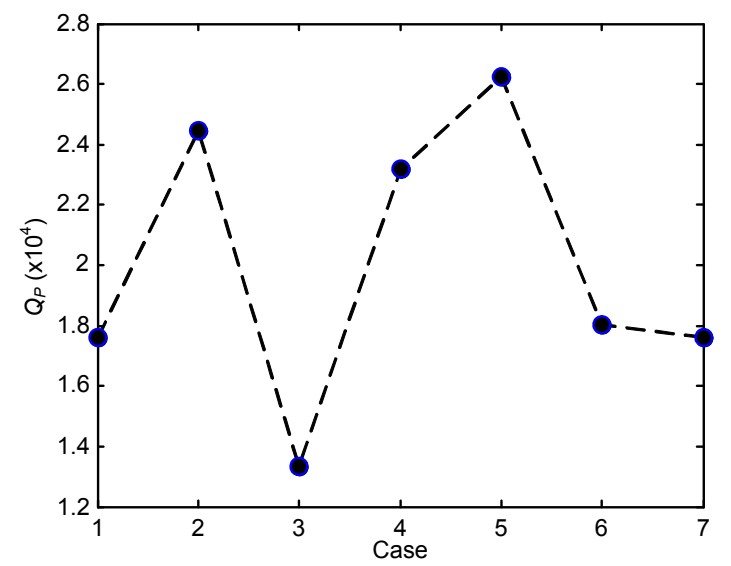

Fig. 18 Heat transfer and pressure ratio under seven kinds of fin arrangement calculate fluid viscosity between wall and turbulent area, in which the modification to the turbulent model can be ignored and the calculation on the turbulent area can be simplified.

The value of Y plus of seven kinds of fin arrangement near the wall after calculation is shown in Fig. 19.

From the above results, we find that the value of Y plus for the seven fin arrangements is mainly in the range of $0-700$, and most of those are in the range of 100-400. From the Fluent manual, we know that the value of Y plus should be in the range of 30 to 500, so that, in this study, these results show that the results are valid.

\section{Conclusions}

This study mainly investigated fluid flow and heat transfer at inlet of a plate-fin heat exchanger under different fin arrangements. The CFD model of the plate-fin heat exchanger was created and 18 kinds of fin arrangement under single layer were analyzed. The following conclusions flow from the above analysis:

Fin arrangements in three sections affect fluid turbulence. Simulating the fluid flow under seven fin arrangements shows that, with increase of fin number, turbulence intensity at monitoring positions decreases along the flow direction, and the intensity difference between the inlet and outlet is up to $92.6 \%$.

Dense arrangement of fins can equalize fluid distribution in different channels at the same layer, reduce temperature difference, increase the heat exchange area of fins, and improve the effect of heat transfer.

Compared with the inlet and heat exchange sections, fin arrangements in the diversion section have more significant effects on temperature distribution and pressure drop.

The mean value of pressure drop at the outlet is consistent with temperature. In three sections, when the mean value of temperature at the outlet reduces to the minimum, the pressure also nearly reaches to the minimum which means the pressure drop is at its maximum. 

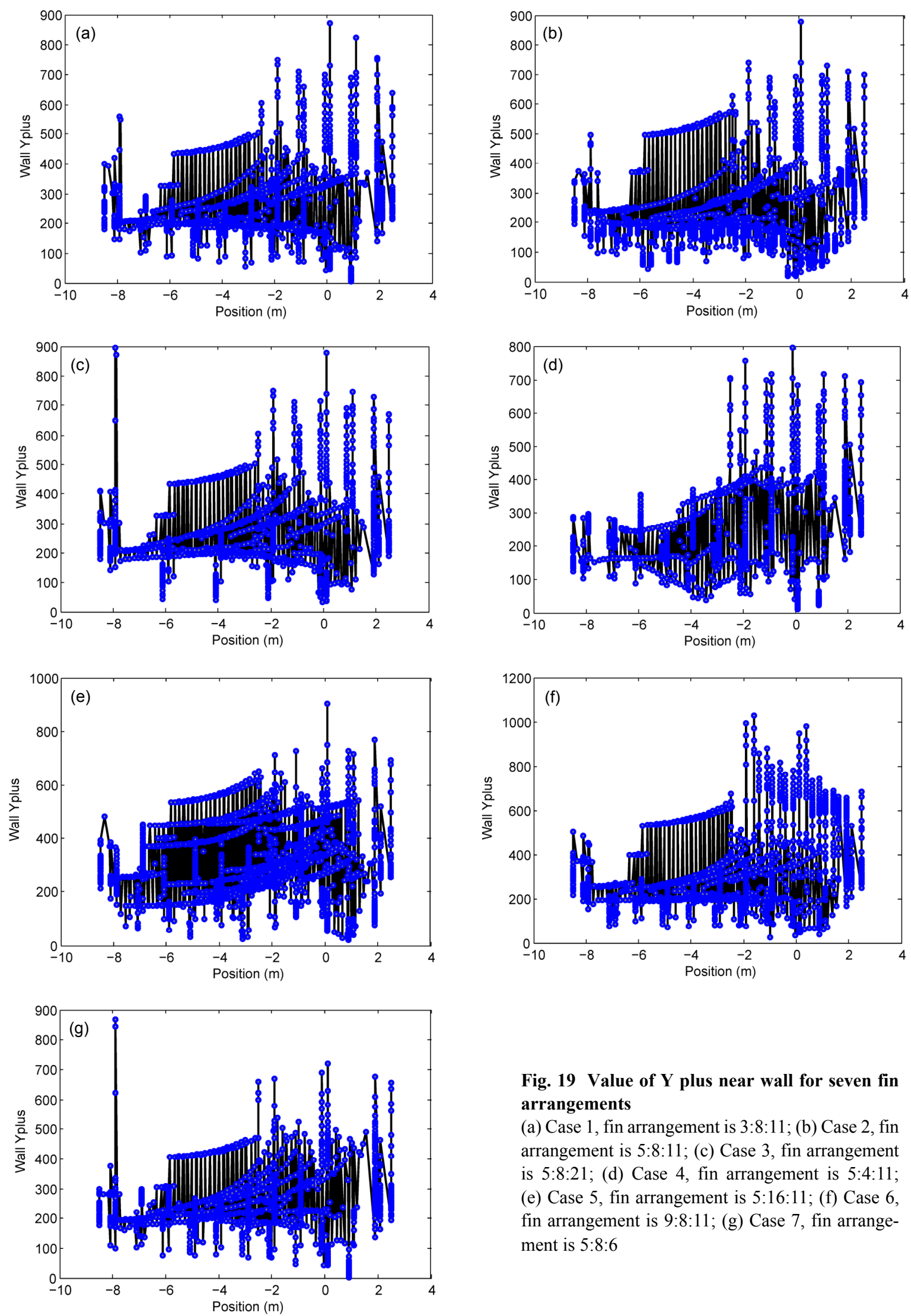

Fig. 19 Value of $Y$ plus near wall for seven fin arrangements

(a) Case 1, fin arrangement is 3:8:11; (b) Case 2, fin arrangement is $5: 8: 11$; (c) Case 3 , fin arrangement is $5: 8: 21$; (d) Case 4, fin arrangement is 5:4:11; (e) Case 5, fin arrangement is 5:16:11; (f) Case 6, fin arrangement is $9: 8: 11$; (g) Case 7, fin arrangement is $5: 8: 6$ 


\section{References}

Al-Waked, R., Nasif, M.S., Morrison, G., et al., 2013. CFD simulation of air to air enthalpy heat exchanger. Energy Conversion and Management, 74:377-385. [doi:10.1016/ j.enconman.2013.05.038]

Gao, X.M., Li, W.Y., Wang, J.S., 2012. Flow and heat transfer characteristics of low flow resistance surface. Chinese Journal of Mechanical Engineering, 48(08):128-134 (in Chinese). [doi:10.3901/JME.2012.08.128]

Gnanasekaran, N., Balaji, C., 2011. A bayesian approach for the simultaneous estimation of surface heat transfer coefficient and thermal conductivity from steady state experiments on fins. International Journal of Heat and Mass Transfer, 54(13-14):3060-3068. [doi:10.1016/j. ijheatmasstransfer.2011.01.028]

Gullapalli, V.S., Sundén, B., 2014. CFD simulation of heat transfer and pressure drop in compact brazed plate heat exchanger. Heat Transfer Engineering, 35(4):358-366. [doi:10.1080/01457632.2013.828557]

He, Y.L., Tao, W.Q., 2009. Fundamental mechanism of enhancing single-phase convective heat transfer. Chinese Journal of Mechanical Engineering, 45(03):27-38 (in Chinese). [doi:10.3901/JME.2009.03.027]

Hu, H.G., Zhang, C., 2007. A modified $k-\varepsilon$ turbulence model for the simulation of two-phase flow and heat transfer in condensers. International Journal of Heat and Mass Transfer, 50(9-10):1641-1648. [doi:10.1016/j.ijheatmasstransfer. 2006.10.031]

Huang, Y.Q., Yu, X.L., Lu, G.D., 2008. Numerical simulation and optimization design of the EGR cooler in vehicle. Journal of Zhejiang University-SCIENCE A, 9(9):12701276. [doi:10.1631/jzus.A0820223]

Huang, Y.Q., Huang, R., Yu, X.L., 2013. Simulation, experimentation, and collaborative analysis of adjacent heat exchange modules in a vehicular cooling system. Journal of Zhejiang University-SCIENCE A (Applied Physics \& Engineering), 14(6):417-426. [doi:10.1631/jzus. A1300038]

Kundu, B., Bhanja, D., Lee, K.S., 2012. A model on the basis of analytics for computing maximum heat transfer in porous fins. International Journal of Heat and Mass Transfer, 55(25-26):7611-7622. [doi:10.1016/j.ijheatmasstransfer. 2012.07.069]

Li, X.W., Meng, J.A., Li, Z.X., 2011. Roughness enhanced mechanism for turbulent convective heat transfer. International Journal of Heat and Mass Transfer, 54(9-10):1775-1781. [doi:10.1016/j.ijheatmasstransfer. 2010.12.039]

Lin, Q.Y., Li, P.N., Lin, R.D., et al., 2004. Study on the heat transfer enhancement by the hydraulic turbine in a tube. Chinese Journal of Mechanical Engineering, 40(05): 165-169 (in Chinese). [doi:10.3901/JME.2004.05.165]

Liu, J.C., Zhang, S.Y., Zhou, Z.Y., 2014. Analysis of channel structure improvement and its influence on fluid flow in plate-fin heat exchanger. Chinese Journal of Mechanical Engineering, 50(18):167-176 (in Chinese). [doi:10.3901/ JME.2014.18.167]

Liu, Z.M., Pang, Y., Shen, F., 2012. Effects of geometry on liquid flow and heat transfer in microchannels. Chinese Journal of Mechanical Engineering, 48(16):139-142 (in Chinese). [doi:10.3901/JME.2012.16.139]

Lozza, G., Merlo, U., 2001. An experimental investigation of heat transfer and friction losses of interrupted and wavy fins for fin-and-tube heat exchangers. International Journal of Refrigeration, 24(5):409-416. [doi:10.1016/ S0140-7007(00)00035-9]

Ma, Y.F., Yuan, Y.C., Liu, Y.Z., et al., 2011. Effect of longitudinal pitch on heat transfer and flow resistance characteristics of serrated spiral-finned-tube banks. Chinese Journal of Mechanical Engineering, 47(08):163-168 (in Chinese). [doi:10.3901/JME.2011.08.163]

Qiu, J., Wei, W.J., Zhang, S.Z., et al., 2010. Research on performance of distributors used in plate heat exchangers based on CFD numerical simulation. Chinese Journal of Mechanical Engineering, 46(14):130-137 (in Chinese). [doi:10.3901/JME.2010.14.130]

Sahiti, N., Durst, F., Dewan, A., 2005. Heat transfer enhancement by pin element. International Journal of Heat and Mass Transfer, 48(23-24):4738-4747. [doi:10.1016/j. ijheatmasstransfer.2005.07.001]

Wang, J.S., Liu, Z.Y., Zhang, J.F., et al., 2007. Large eddy simulation on heat transfer enhancement of inclined-cut ellipsoidal vortex generator. Chinese Journal of $\mathrm{Me}$ chanical Engineering, 43(10):55-61 (in Chinese). [doi:10. 3901/JME.2007.10.055]

Wongwises, S., Chokeman, Y., 2005. Effect of fin pitch and number of tube rows on the air side performance of herringbone wavy fin and tube heat exchangers. Energy Conversion and Management, 46(13-14):2216-2231. [doi:10.1016/j.enconman.2004.09.011]

Yang, K.S., Chu, W.H., Chen, I.Y., et al., 2007. A comparative study of the airside performance of heat sinks having pin fin configurations. International Journal of Heat and Mass Transfer, 50(23-24):4661-4667. [doi:10.1016/j. ijheatmasstransfer.2007.03.006]

Yang, Y.C., Chen, W.L., 2009. An iterative regularization method in simultaneously estimating the inlet temperature and heat-transfer rate in a forced-convection pipe. International Journal of Heat and Mass Transfer, 52(7-8): 1928-1937. [doi:10.1016/j.ijheatmasstransfer.2008.11. 001]

Yang, Y.T., Hwang, M.L., 2009. Numerical simulation of turbulent fluid flow and heat transfer characteristics in heat exchangers fitted with porous media. International Journal of Heat and Mass Transfer, 52(13-14):2956-2965. [doi:10.1016/j.ijheatmasstransfer.2009.02.024]

Zhang, L., Qian, H.W., Yu, X.M., et al., 2007. Heat transfer enhancement mechanism of heat exchanger tubes with 
rotating twisted tape insert. Chinese Journal of Mechanical Engineering, 43(01):139-143 (in Chinese). [doi:10. 3901/JME.2007.01.139]

Zhang, X.B., Chen, J.Y., Yao, L., et al., 2014. Research and development of large-scale cryogenic air separation in China. Journal of Zhejiang University-SCIENCE A (Applied Physics \& Engineering), 15(5):309-322. [doi:10. 1631/jzus.A1400063]

\section{中文概要}

题 目: 板翅换热器入口位置不同翅片排列方式对流体流 动与换热的影响

目 的: 研究板翅换热器入口位置 (入口段、导流段以及 换热段）在不同翅片排列方式下，换热器流道内 流体流动以及温度变化情况, 期望得到能够实现
最优传热效果的板翅换热器入口位置合理的翅 片排列方式。

方 法: 1. 构建 7 种不同入口翅片排列 (入口段: 导流段: 换热段分别为 $5: 8: 11 ， 5: 8: 6 ， 5: 8: 21 ， 5: 4: 11$, $5: 16: 11,9: 8: 11$ 和 $3: 8: 11$ ), 研究不同翅片排列下 换热器入口位置流场以及温度场变化。2. 分析板 翅换热器入口位置 6 种不同网格划分结果 (网格 数分别为 $11962,39344,2120,207998,90738$ 和 54496）对计算误差的影响, 验证网格收玫性。

结 论: 通过分析板翅换热器入口位置不同翅片排列方式 下换热器入口位置流场与温度场变化可以看出, 相比入口段与换热段, 导流段翅片排列对换热器 温度场影响较大。强化导流段翅片排列可以使换 热器获得更好的传热效果。

关键词：翅片排列; 板翅换热器; 传热; 湍流; 温度均衡 